Neurosurg Focus 9 (3):E4, 2000

\title{
Surgical approach to posterior skull deformity
}

\author{
Francis R. Johns, D.M.D., M.D., John A. Jane, SR., M.D., Ph.D., F.R.C.S.(C), \\ AND KANT Y. LIN, M.D. \\ Departments of Plastic Surgery and Neurological Surgery, University of Virginia Health Sciences \\ Center, Charlottesville, Virginia
}

\begin{abstract}
The incidence of occipital skull flattening in infants has recently increased, partly as a result of widespread supine positioning to prevent sudden infant death syndrome. The authors discuss the causes and differential diagnosis of posterior skull deformity in this subpopulation of patients and describe their technique for surgical correction of the condition.
\end{abstract}

KEY WORDS • posterior skull deformity - surgical approach $・$ infant

Many craniofacial centers have recently seen a dramatic increase in the number of referrals for evaluation of either unilateral or bilateral occipital skull flattening in infants. The majority of these cases are now recognized as being the result of supine positioning of infants rather than cases of true craniosynostosis., ${ }^{2,17}$ In 1992, the American Academy of Pediatrics issued a position paper $^{1}$ recommending that infants be placed on either their backs or sides when sleeping to avoid the possible occurrence of SIDS. Although this practice has played a significant role in decreasing the incidence of SIDS, the unfortunate corollary has been a concomitant rise in the incidence of posterior plagiocephaly, which has been attributed to the molding effects on the immature skull of external pressures associated with supine positioning. The increased incidence of this disorder has led to greater awareness of skull shapes and growth processes by both the pediatric medical community and the lay public. An additional recognized cause of nonsyndromic head deformity, congenital occipitoparietal deformation is an in utero process involving external compressional forces exerted against the posterior cranium by the adjacent lumbosacral spine or by other abnormal uterine constraints associated with such conditions as oligohydramnios, uterine malformation, fetal malposition, and/or multiple fetuses. ${ }^{3,5}$

The incidence of true synostotic posterior plagiocephaly - that is, isolated lambdoid suture synostosis - remains extremely rare in comparison with that of deformational posterior plagiocephaly, with the former accounting for less than $3 \%$ of all cases. ${ }^{7}$ In this report we address the dis-

Abbreviations used in this paper: $\mathrm{CT}=$ computerized tomography; SIDS = sudden infant death syndrome. tinctions between these disparate causes of posterior skull flattening and discuss their implications for the treatment of these deformities.

\section{DIFFERENTIAL DIAGNOSIS}

Deformational posterior plagiocephaly usually be reliably differentiated from synostotic posterior plagiocephaly by careful history taking and a thorough physical examination alone. Plain X-ray films or CT scans may help confirm the diagnosis but are not essential.

Huang and coworkers ${ }^{7}$ evaluated 102 patients with posterior plagiocephaly and reported significant differences in the characteristics of each patient's skull deformity. Patients with synostotic plagiocephaly had trapezoid-shaped heads when viewed from the vertex instead of the parallelogram shape noted in deformational plagiocephaly (Fig. 1); the skull shape of these same patients was that of a parallelogram when viewed posteriorly. The latter deformity resulted from the fact that contralateral posterior bossing had occurred more laterally and superiorly, as had ipsilateral occipitomastoid bossing; both abnormalities were the effects of compensatory growth around the fused suture. This finding was consistent with postulated compensations associated with the premature closure of other cranial sutures. Frontal bossing was not a striking feature of synostotic plagiocephaly, but when present its site was contralateral. Ipsilateral frontal bossing was consistently noted in patients with deformational plagiocephaly. The ipsilateral ear in patients with synostotic plagiocephaly was generally observed to be displaced posteriorly toward the fused suture instead of anteriorly away from the suture, as is seen in deformational plagiocephaly. 

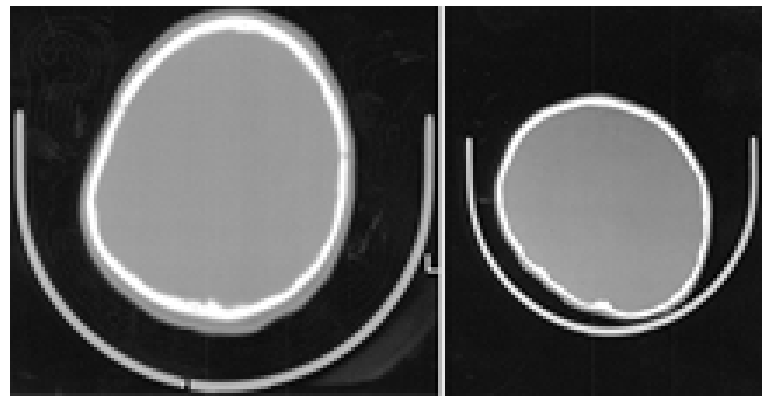

Fig. 1. Axial CT scans demonstrating difference between synostotic posterior plagiocephaly (left) and deformational posterior plagiocephaly (right).

In their study of 115 infants with posterior skull deformities, Mulliken and coworkers ${ }^{14}$ found more subtle dysmorphic features differentiating the two types of posterior plagiocephaly. These authors noted ipsilateral posterior flattening and contralateral parietooccipital bossing to be more severe in patients with synostotic plagiocephaly. They also noted that the external ear canal was anteriorly displaced in deformational posterior plagiocephaly but variably displaced in synostotic posterior plagiocephaly.

This constellation of findings can usually lead the astute clinician to a correct diagnosis. Roentgenographic confirmation of the diagnosis is rarely necessary, but important findings on radiological imaging in synostotic plagiocephaly include an endocranial ridging of the synostosed suture or an actual effacement of the suture itself, described as a sclerotic suture, which is not seen in deformational cases.

The choice of treatment for the deformity is dictated by the severity of the manifestation of the process involved, both at the primary site and in any compensatory changes seen in distant secondary regions as reflected in the overall shape of the skull, rather than solely by the immediate origin of the deformity. Thus, treatment remains a judgment call to be determined by both parents and treating physicians in close discussion.
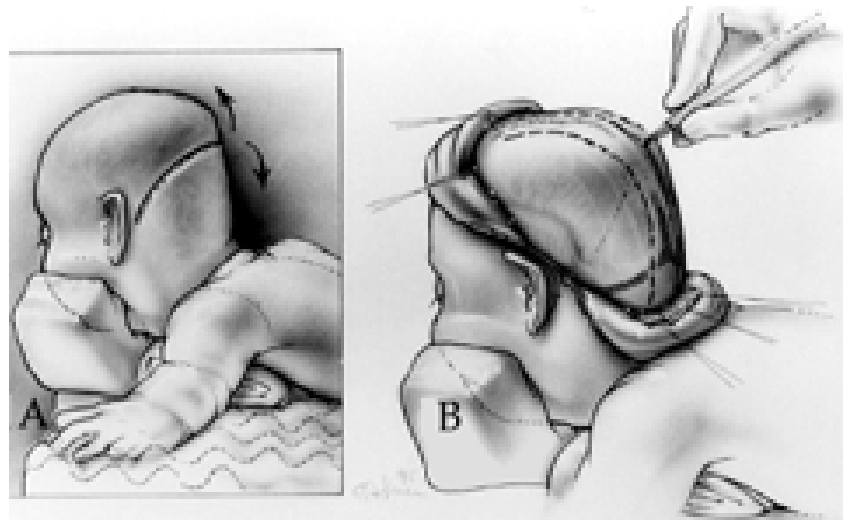

Fig. 2. Artist's illustrations depicting initial stages of surgical procedure for correction of posterior plagiocephaly. A: Infant is placed in prone position; initial incision is made. B: Scalp flaps are elevated and medial bone strut is outlined.

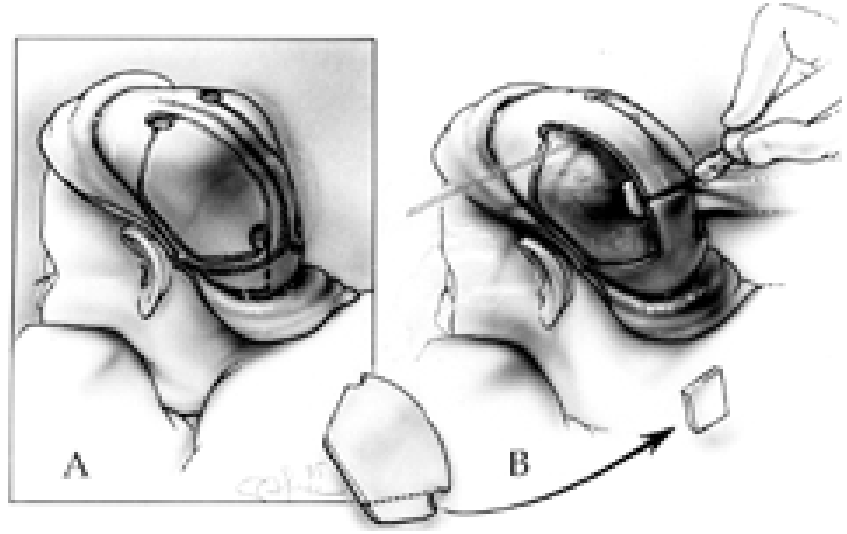

Fig. 3. Artist's illustrations depicting bihemispheric occipital bone osteotomies (A) and osteotomy of medial bone strut (B). A suitably shaped piece of bone for medial strut grafting is cut from either of the occipital hemisphere segments (inset).

\section{Treatment of Deformational Posterior Plagiocephaly}

In 1979, Clarren, et al., ${ }^{4}$ introduced the use of helmetmolding therapy for the treatment of deformational plagiocephaly, with mixed results. Surgical management remained the mainstay of treatment until recently, when several craniofacial centers reported improved results by using conservative measures alone (unpublished data). ${ }^{9,15,17}$ Nonsurgical measures included frequent head turning, positioning with foam wedges, and prone positioning once the infant was older than 6 months of age, as well as ruling out other causes that might lead the child to favor one side of the head, such as a torticollis from cervical spine problems, strap muscle pathology, or vision problems (for example, a squint). The major advance, however, has been in the refinement of helmet-molding therapy. Both active and passive varieties of this therapeutic modality have been advocated. Dynamic orthotic compression devices have been developed that allow much more precision in molding the immature calvarium, with very encouraging results. However, this treatment can be quite costly and its superiority over passive molding has yet to be conclusively proven.

There is a subset of infants who suffer from severe and aesthetically unacceptable deformational posterior plagiocephaly or who are too old to be treated successfully by using conservative measures (unpublished data). ${ }^{11}$ Surgical intervention is indicated in these patients if at least 6 months of conservative treatment elapse without evidence of improvement. The surgical procedure is the same as that used for the correction of synostotic posterior plagiocephaly. In our experience over the last 3 years, we have evaluated 73 patients for deformational posterior plagiocephaly. Helmet-molding therapy was successful in correcting the deformity in 67 of these patients; however, in six patients the condition did not respond to conservative measures and surgical correction was required.

\section{Treatment of Synostotic Posterior Plagiocephaly}

The accepted method of treatment for synostotic posterior plagiocephaly is surgical intervention, but again, this depends on the severity of the overall skull deformity. We 

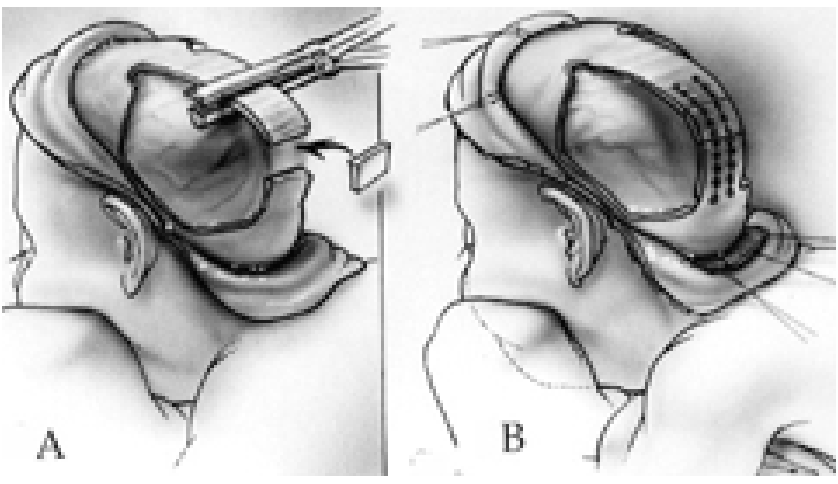

Fig. 4. Artist's illustrations depicting lengthening of medial bone strut with bone graft placement $(\mathrm{A})$ and fixation of strut and graft with absorbable plate and screws (B).

have followed patients with known true lambdoid synostosis for whom we have not recommended surgical correction. Previously described techniques for surgical correction include isolated strip craniectomies, limited cranioplasties with reversal and rotation of bone segments, and extensive total cranial vault cranioplasties with barrel-stave osteotomies to reshape the affected bones. ${ }^{6,8}$, $10,12,13,16,18$ Additionally, prolonged prone positioning is required in the postoperative period. In most cases, a more extensive cranioplasty is needed to correct all primary and compensatory problems involved in lambdoid synostosis.

The surgical technique for correction of posterior plagiocephaly varies depending on the surgeon, the morphological structure of the individual patient, and whether the deformity is unilateral or bilateral. Our procedure begins with a bicoronal incision and elevation of a subperiosteal posterior scalp flap. After exposure of the parietal and occipital bones, a median strut of occipital bone is marked out and two posterior hemispheric craniotomies are performed on either side of the strut (Figs. 2-5). Dissection and separation of the sagittal and transverse sinuses from the underside of this strut allow it to be safely osteotomized. A preoperative three-dimensional venogram is also obtained to permit better visualization and localization of the sinuses, thus increasing the safety of these

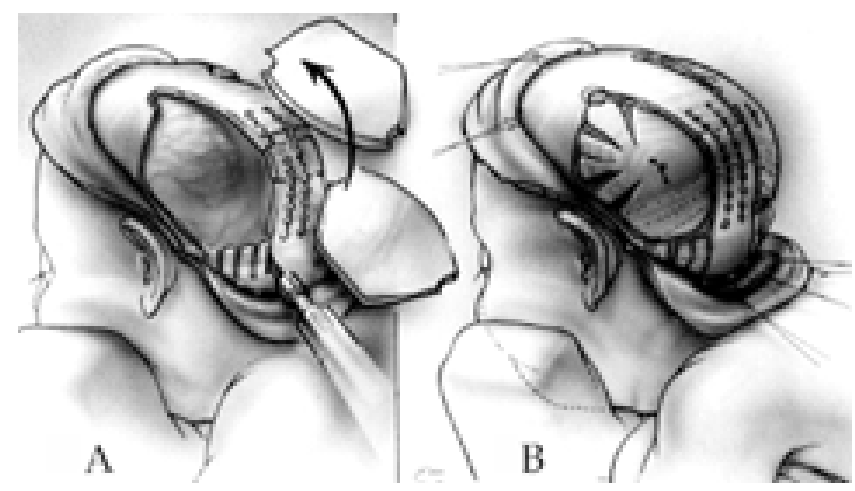

Fig. 5. Artist's illustrations depicting barrel-stave osteotomies of occipital bone and bone flaps (A) and suturing of bone flaps into place with absorbable thread (B).

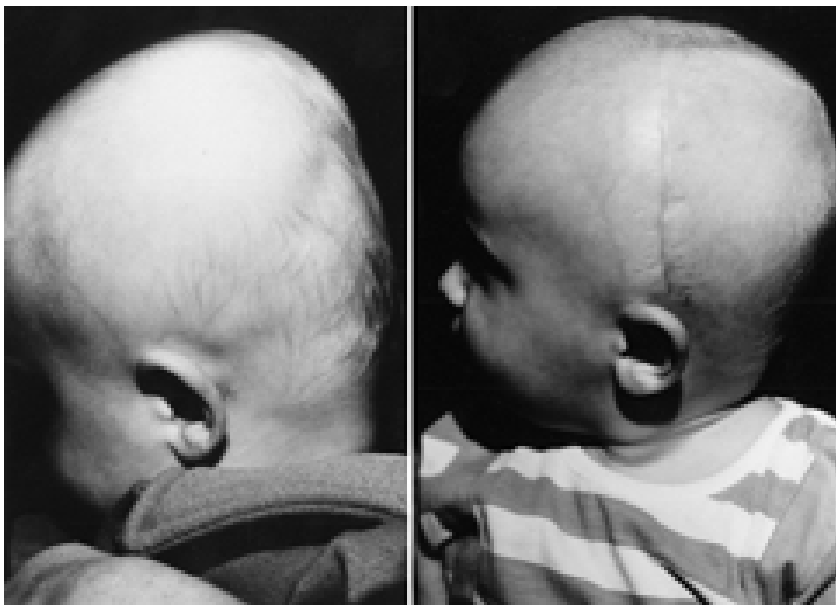

Fig. 6. Photographs obtained in an infant showing posterior skull deformity preoperatively (left) and the result 1 year postoperatively (right).

stages in the procedure. The remaining median strut is then reshaped into a more anatomically appropriate convex curve, which is rigidly fixed and maintained with an absorbable microplate and screw fixation. Placement of a bone graft is often required to fill in the increased curvature of the strut; for this purpose a suitably shaped piece of bone is harvested from either of the two occipital segments and fixed in place in the osteotomized segment of the median strut. The two posterior occipital hemispheres are likewise reshaped with Tessier bone benders, and barrel-stave osteotomies are created along their peripheries. These segments are then returned to their orthotopic positions and attached by absorbable suture to the central bone strut to allow for enough flexibility to accommodate further brain growth and expansion. The strut acts as a scaffold from which these segments are suspended. The patient is kept prone for the first 48 hours, but after that time there are no restrictions on the patient's positioning. Potential risks associated with this procedure include dural tears, sagittal sinus laceration, cerebral edema, and postoperative meningitis. in our experience this procedure has proven to be safe, with no incidences of mortality or morbidity, and has provided excellent cosmetic results (Figs. 6 and 7).
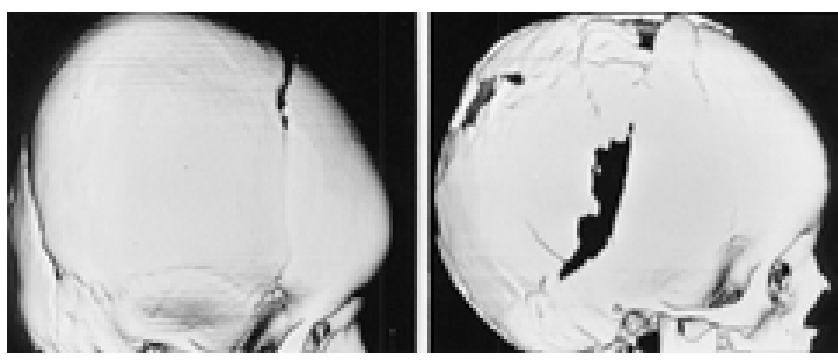

Fig. 7. Axial three-dimensional CT scans obtained in an infant, demonstrating posterior skull deformity preoperatively (left) and the result 1 year after corrective surgery (right). 


\section{CONCLUSIONS}

Posterior skull deformities are most often due to positional molding resulting in deformational posterior plagiocephaly. This is evidenced by the fact that the recent increased incidence of this deformity coincides with the Academy of Pediatrics Position Statement recommending supine positioning of infants to prevent SIDS. The vast majority of these cases can be managed with conservative measures including positional changes and helmet molding. Surgical intervention is only required in the cases of severe deformational deformity in which these conservative measures fail. Synostotic posterior plagiocephaly represents a very small proportion of posterior skull deformities. Although conservative measures such as helmetmolding will not be effective in treating this disorder, the decision to pursue operative correction is again based on the severity of the condition and not exclusively on the cause of the deformity. We describe a surgical technique that we have found to be a safe means of treating posterior skull deformities in infants, and one that can provide excellent long-term aesthetic results.

\section{References}

1. American Academy of Pediatrics Task Force on Infant Positioning and SIDS: Positioning and SIDS. Pediatrics 89: 1120-1126, 1992

2. Argenta LC, David LR, Wilson JA, et al: An increase in infant cranial deformity with supine sleeping position. J Craniofac Surg 7:5-11, 1996

3. Bruneteau RJ, Mulliken JB: Frontal plagiocephaly: synostotic, compensational, or deformational. Plast Reconstr Surg 89: 21-33, 1992

4. Clarren SK, Smith DW, Hanson JW: Helmet treatment for plagiocephaly and congenital muscular torticollis. J Pediatr 94: 43-46, 1979

5. Hansen M, Mulliken JB: Frontal plagiocephaly. Diagnosis and treatment. Clin Plast Surg 21:543-553, 1994

6. Hinton DR, Becker LE, Muakkassa KF, et al: Lambdoid synostosis. Part 1. The lambdoid suture: normal development and pathology of "synostosis.” J Neurosurg 61:333-339, 1984
7. Huang MH, Gruss JS, Clarren SK, et al: The differential diagnosis of posterior plagiocephaly: true lambdoid synostosis versus positional molding. Plast Reconstr Surg 98:765-776, 1996

8. Jane JA, Persing JA: Neurosurgical treatment of craniosynostosis, in Cohen MM (ed): Craniosynostosis: Diagnosis, Evaluation and Management. New York: Raven Press, 1986, pp 249-320

9. Jimenez DF, Barone CM: The sunrise technique: the correction of occipital plagiocephaly using bandeau occipital plate and radial osteotomies. Pediatr Neurosurg 22:162-166, 1995

10. Jimenez DF, Barone CM, Argamaso RV, et al: Asterion region synostosis. Cleft Palate Craniofac J 31:136-141, 1994

11. Lin KY, Nolen AA, Gampper TG, et al: Elevated levels of transforming growth factors beta 2 and beta 3 in lambdoid sutures from children with persistent plagiocephaly. Cleft Palate Craniofac J 34:331-337, 1997

12. McComb JG: Treatment of functional lambdoid synostosis. Neurosurg Clin North Am 2:665-672, 1991

13. Muakkassa KF, Hoffman HJ, Hinton DR, et al: Lambdoid synostosis. Part 2: Review of cases managed at the Hospital for Sick Children, 1972-1982. J Neurosurg 61:340-347, 1984

14. Mulliken JB, Vander Woude DL, Hansen M: Analysis of posterior plagiocephaly: deformational versus synostotic. Plast Reconstr Surg 103:371-380, 1999

15. Ripley CE, Pomatto J, Beals SP, et al: Treatment of positional plagiocephaly with dynamic orthotic cranioplasty. J Craniofac Surg 5:150-160, 1994

16. Persing JA, Delashaw JB, Jane JA, et al: Lambdoid synostosis: surgical considerations. Plast Reconstr Surg 17: 852-860, 1988

17. Turk AE, McCarthy JG, Thorne CHM, et al: The "back to sleep campaign" and deformational plagiocephaly: is there cause for concern? J Craniofac Surg 7:12-18, 1996

18. Vander Kolk CA, Carson BS: Lambdoid synostosis. Plast Clin North Am 21:575-584, 1994

Manuscript received July 24, 2000.

Accepted in final form August 16, 2000.

Address reprint requests to: Kant Lin, M.D., Department of Plastic Surgery, University of Virginia Health Sciences Center, Box 800376, Charlottesville, Virginia 22908. email:kyl5s@ virginia.edu. 